\title{
Dart formation in nematocysts of the sea anemone Metridium senile (Linnaeus, 1761) (Cnidaria: Anthozoa)
}

\author{
CARINA ÖSTMAN ${ }^{1}$, JENS ROAT KULTIMA ${ }^{2}$ and SAU YU GRACE WONG ${ }^{3}$ \\ ${ }^{1}$ Animal Development and Genetics, Evolutionary Biology Centre (EBC), Uppsala University, Norbyvägen 18A, \\ SE-752 36 Uppsala, Sweden, E-mail: Carina.Ostman@ebc.uu.se \\ ${ }^{2}$ Uppsala University, Norbyvägen 18A, SE-752 36 Uppsala, Sweden. \\ ${ }^{3}$ School of Animal and Microbial Sciences, University of Reading, P.O. Box 228, Reading, RG6 6AJ, UK.
}

\begin{abstract}
SUMMARY: In examining large acontia b-mastigophore and p-amastigophore nematocysts of the sea anemone Metridium senile (Linnaeus, 1761) darts were observed by interference-contrast light microscopy (LM) and scanning electron microscopy (SEM). The darts consist of closely packed spines detached from the shafts, still in three helical rows. Their spines form a hollow cylinder with a sharp tip and indented base, its width similar to that of an undischarged shaft but varying in length. b-mastigophore darts were more common than those of p-mastigophores and many were longer.
\end{abstract}

Keywords: nematocysts, cnidae, sea anemones, darts, SEM.

RESUMEN: Formación de los DARdos en los Nematocistos De la anémona de MAR Metridium SENILE (Linnaeus, 1761) (CNIDARIA: ANTHOZOA). - El examen mediante microscopía de contraste de fases (LM) y microscopio electrónico de barrido (MEB) de los grandes nematocistos acontios b-mastigóforos y p- amastigóforos de la anémona de mar Metridium senile (Linnaeus, 1761) permitió la observación de dardos. Los dardos consisten en espinas fuertemente empaquetadas desligadas de la punta del dardo, todavía en tres hileras helicoidales. Sus espinas forman un cilindro hueco con una punta afilada y una base no dentada, su anchura es similar a la de la punta de un dardo no descargado, pero varían en longitud. Los dardos b-mastigióforos fueron más frecuentes que los de p-mastigióforos y muchos de ellos fueron más largos.

Palabras clave: nematocistos, cnidoma, anémona de mar, dardos, MEB.

\section{INTRODUCTION}

Anthozoan b-mastigophore, p-mastigophore and p-amastigophore nematocysts can form darts. They have been found in the actinian genera Aiptasia (Iwanzoff, 1896; Cutress, 1955; Schmidt, 1969; Conklin et al., 1977; England, 1982), Anemonia (Weill, 1934), Metridium (Weill, 1934; Cutress, 1955; Schmidt, 1969; Östman, 2000), Diadumene (Hand, 1961; Schmidt; 1969), Sagartiogeton (Schmidt, 1969; Östman et al., in preparation), Bartholomea and Bunodeopsis (Conklin et al., 1977), and in the solitary coral Caryophyllia smithii (England, 1982).

The mechanism of dart formation have remained uncertain. Iwanzoff (1896) described the darts associated with certain mastigophores from the sea anemone
Aiptasia diaphana. He regarded the darts as a fusion product of some of the armature shed from the nematocyst tubule. Weill (1934) described and illustrated dart-shaped structures in Metridium senile (as Actinoloba dianthus) formed in microbasic mastigophores and microbasic amastigophores from groups of spines detached from the shaft. He noted that a long, single dart might dissociate into several. Iwanzoff and Weill considered darts to be something of an anomaly among nematocysts.

Cutress (1955) regarded Iwanzoff and Weill's interpretation of dart formation to be illogical. He considered darts to be too precise a structure to be formed repeatedly by armature sloughed from the shaft and claimed that after ejecting a dart, nematocyst shafts retained their armature (p. 132, Fig. 7). Cutress consid- 
ered the dart to be a discrete structure within capsules of certain nematocysts, for which he introduced the category microbasic q-mastigophore. He illustrated these q-mastigophores in Aiptasia pulchella, showing a dart within the inverted shaft in which it fitted neatly at the tip (p. 132, Fig. 7a-d). Cutress thought the dart was ejected during discharge and pushed aside by the evaginating tubule.

Cutress's interpretation was not accepted by Hand (1961), Schmidt (1969), Conklin et al. (1977) and England (1982). They followed the theory of Iwanzoff and Weill that darts were produced by spines detached from everting shafts, and reported darts lying near a discharged shaft lacking spination.

Schmidt (1969) examined living Metridium senile and Aiptasia diaphana and described darts formed from detached spirals of spines pressed together in brhabdoids (= microbasic b-mastigophores) and p-rhabdoids (= microbasic p-amastigophores). According to Schmidt (p. 295, Fig. 6), elasticity of the tightly folded proximal shaft (= "faltstuck") is crucial in dart formation. He interpreted this process as follows. Normally, eversion of the shaft is caused by high intra-capsular pressure but if evagination is hindered the proximal shaft, compressed under pressure, shortens along its axis. Spines are then torn from the shaft wall, forming darts. When eversion of the shaft continues, a dart will be pushed out of the capsule and more distal spines, not detached from the shaft wall, evert normally (p. 296, Fig. 7h).

Conklin et al. (1977) reported dart formation in three sea anemones: Aiptasia pallida, Bartholomea annulata (acontia and tentacles) and Bunodeopsis antilliensis (tentacles and lower column). They found darts of microbasic p-mastigophores and microbasic amastigophores (= p-amastigophores) and estimated that acontia b-mastigophore darts were about 27 times more frequent than those formed by tentacle amastigophores. Their SEM observations showed that when darts were formed, spines were stripped off the shaft and the denuded portion usually corresponded to the length of the dart. Their SEM picture (p. 164, Fig. 10) showed a dart at the tip of an everted, partly spineless shaft.

England (1982, p. 61) noted eversion of the shaft and dart formation in a Bouin-fixed preparation of Caryophyllia smithii: "As the shaft everted the spines moved forward together and as the shaft turned outward at the tip so the spines moved outwards and backwards. In some cases the spines were stuck together at their tips $[\ldots]$. As the shaft everted further more spines were torn from the shaft, the bunch of spines increased and was carried forward by the shaft [...] pushing the bunch of fused spines to one side".

This paper re-investigates the structure and origin of darts in Metridium senile (Linnaeus, 1761) mainly from large acontia b-mastigophores and p-amastigophores by interference-contrast light micrographs (LMs) and scanning electron micrographs (SEMs). Together with darts we describe and illustrate the helical structure of the shaft, spine-rows and distal tubule of these dartproducing nematocysts. Supporting evidence from medium p-amastigophores and small p-mastigophores are also reported.

\section{MATERIALS AND METHODS}

Squash-preparations were made from living Metridium senile collected from the Gullmarsfjord on the Swedish west coast in June-August 1996-2003. The preparations for nematocyst studies were made by methods of Östman $(1987,1991)$. Materials, microscopes used, nematocyst identification and terminology are as in Östman et al. (2010). At least a hundred darts were seen and at least 30 of these were photographed or measured. Some of the measurements were made on SEMs. Fixed and dried structures measured in SEM are slightly shorter than structures in LM squashes made from fresh material.

\section{RESULTS}

\section{Dart-forming nematocysts}

Darts (Figs. 1a, inset, c, 4, 7) are formed from large mesobasic b-mastigophores (Figs. 1a, 2-4) and large micro- and mesobasic p-amastigophores (Figs. $1 \mathrm{~b}, 5 \mathrm{a}, \mathrm{b}, 6)$ of acontia, and also from medium tentacle p-amastigophores (Fig. 1c) and small, microbasic, mesentery p-mastigophores (Fig. 1d). These nematocysts are classified and characterized as follows (for further details see Östman et al., 2010):

1. Mesobasic b-mastigophores, large; capsule narrow, elongate; from acontia (Fig. 1a). Inverted shaft a distinct thin rod; border between proximal and main shaft regions indistinct. Mesobasic shaft approximately twice capsule length (Figs. 2a,c, 3a). Corresponding to dart-forming microbasic mastigophores from $M$. senile (as A. dianthus) (Weill, 1934, p. 144, Figs. 123-125) and to b-rhabdoids from M. senile (Schmidt, 1969, p. 295, Fig. 6).

2. Micro- and mesobasic p-amastigophores, large and medium; capsule, narrow elongate; large ones in acontia only (Figs. 1b, 6); medium ones in tentacles (Fig. 1c). Inverted shaft broad, rod-shaped, border between proximal shaft and main shaft distinct; V-shaped notch with tiny tubule at end of main shaft (Fig. 1b). Characteristic internal structure of matrix (Fig. 1b). Shaft heterotrichous. Corresponding to dart-forming microbasic amastigophores from M. senile (as A. dianthus) (Weill, 1934, p. 144, Figs. 121, 122) and to p-rhabdoids from M. senile (Schmidt, 1969, pp. 295, 302, Figs. 5, 9b).

3. Microbasic p-mastigophores, small; capsule drop-shaped; characteristic of mesenteries (Fig. 1d). Inverted shaft rod-shaped with distal V-shaped notch, not differentiated in proximal and main shaft (Fig. 1d). 

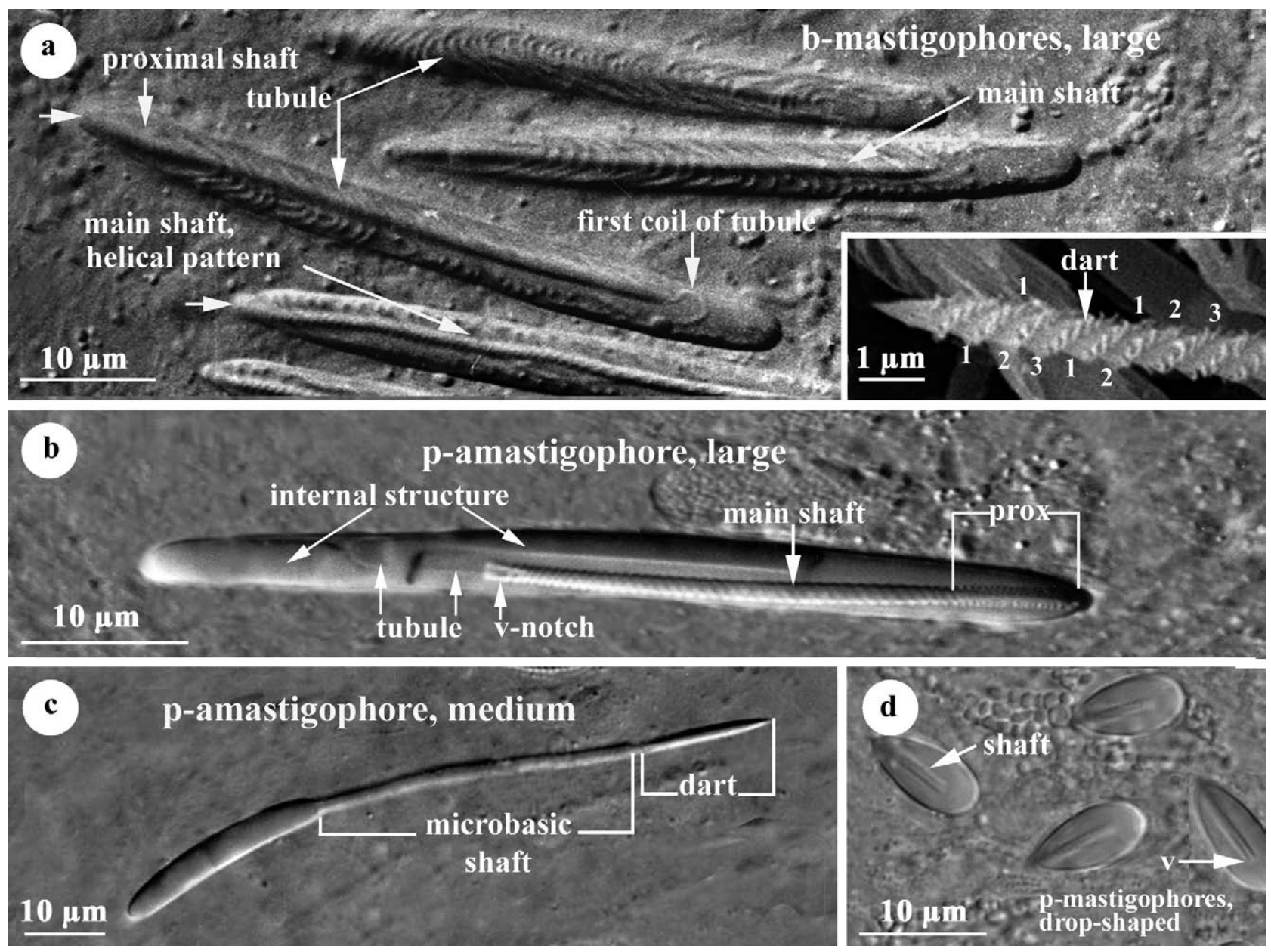

FIG. 1. - Dart forming nematocysts and a dart (SEM). a) Acontia mesobasic b-mastigophores, large. Differences between proximal and main shaft indistinct. Note left-handed helices on shaft. Inset: Dart showing left-handed helices of 3 spine-rows; spine bases face outwards. b) Acontia p-amastigophore, large; proximal shaft (prox) with tight helices and faintly visible rod inside; main shaft with spaced helices. Note tiny tubule and internal capsule structure. c) Tentacle p-amastigophore, medium; with attached dart. d) Mesentery p-mastigophores, small, drop-shaped. prox, proximal shaft; short arrows point at tip of capsule; $v$, v-notch, V-shaped notch; 1, 2, 3, three spine-rows.

\section{Structure of dart-forming shafts and their tubule}

b-mastigophores. In LM the left-handed helical pattern of the inverted shaft is not as clear on the proximal shaft with tight helices as on the main shaft with spaced helices (Fig. 1a). After eversion the three helical spinerows on the everted shaft are right-handed (Figs. 3be,g, 4a). The spines on the main shaft are dense and point in the direction of eversion (Fig. 3b-d,g), whereas those of the proximal shaft are slightly more spaced and mostly point outwards (Fig. 3e). The spines are large pointed blades with broad bases (Figs. 2b, 3e,g). The shaft-tubule tapers gradually towards the distal tubule (Fig. 3d,g), with a few small spines (Figs. 2b, 3f).

p-amastigophores. The differentiation of the inverted shaft into the proximal shaft with tight helices and the main region with more spaced helices is obvious (Fig. 1b). In LM the helices are seen either as left-handed (Fig. 6f) or right-handed (Fig. 6g), depending on whether the focus is on the front or on the back of the inverted shaft. In LM a thin axial rod is visible within the proximal shaft (Figs. 1b, 6b,c; see Östman et al., 2010). During discharge it forms the pointed rod ahead of the everting shaft (Fig. 6d-f). Inverted shafts, slightly flexed proximally (Fig. 6a, prox), turned out to be microbasic when discharged rather than mesobasic as expected. After discharge, slender spines form sparse rows on the proximal shaft (Fig. 5a, see Östman et al., 2010). The main shaft has long, pointed spines in dense rows (Fig. 5a). In undischarged capsules the tiny distal tubule may be seen (Fig. 1b). During discharge the distal tubule either breaks off and remains in the capsule (Figs. 5a, 6g) or remains connected to the shaft and everts (Fig. 5b).

\section{Formation and structure of darts}

Darts were abundant in some squash-preparations of acontia, whereas in others they were rare or absent. Large mesobasic b-mastigophores in particular produced one or more darts as their long, narrow shafts (length 96.0-145.0 $\mu \mathrm{m}$ ) everted. Sometimes 20-30 b- 

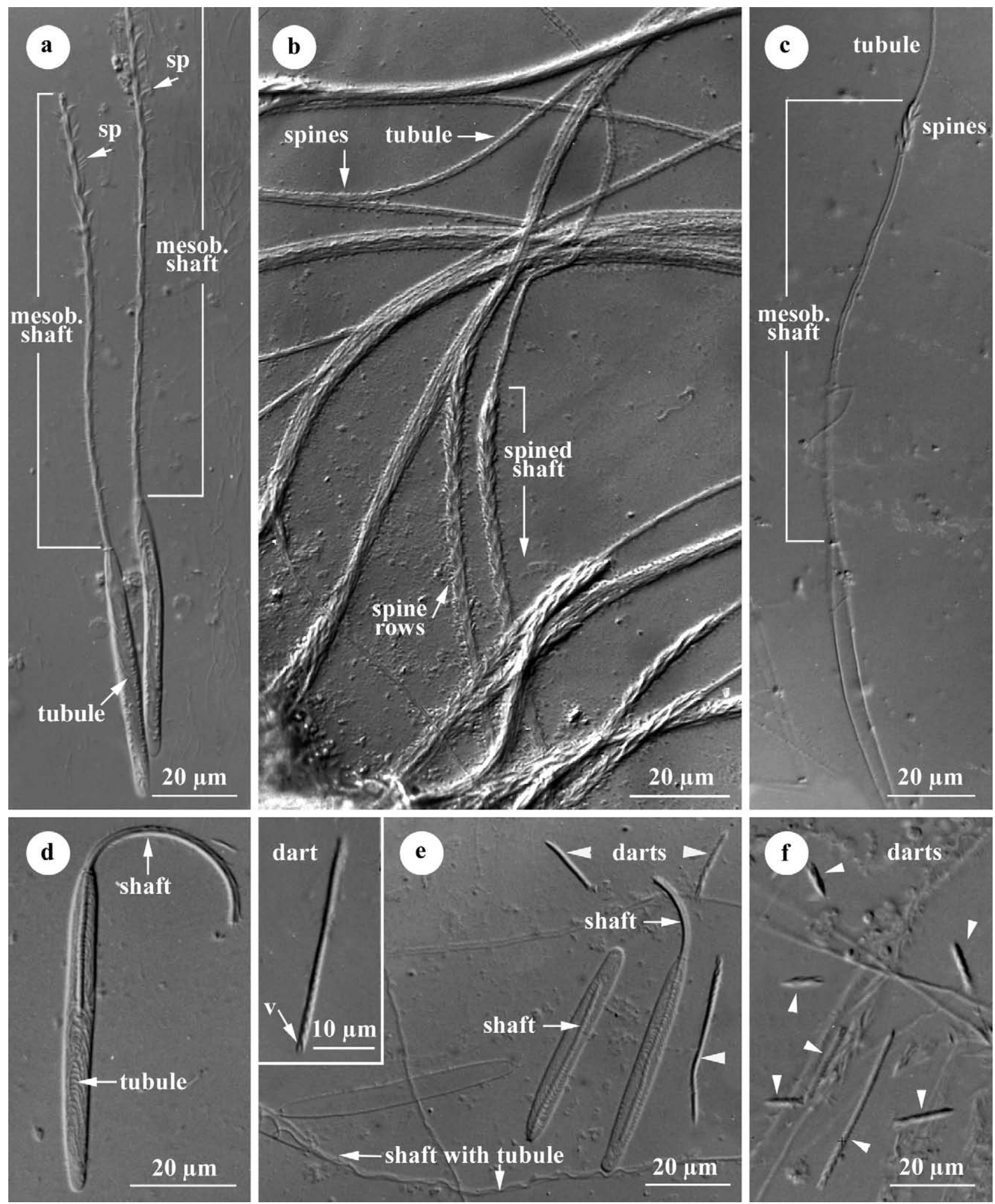

FIG. 2. - Acontia mesobasic b-mastigophores, large, and darts. a) Note inverted tubule inside everted mesobasic shaft and capsule. b) Discharged shafts and tubules. Note conspicuous spine pattern. c) Discharged shaft with distal everted spines and long spineless region. d) Partly discharged shaft. e) Undischarged and partly discharged capsules plus long and short darts. Note tubule inside everted shaft. Inset: A long dart. f) Long and short darts. Arrow heads point at darts; mesob., mesobasic; $s p$, spines; $v$, V-shaped notch. 

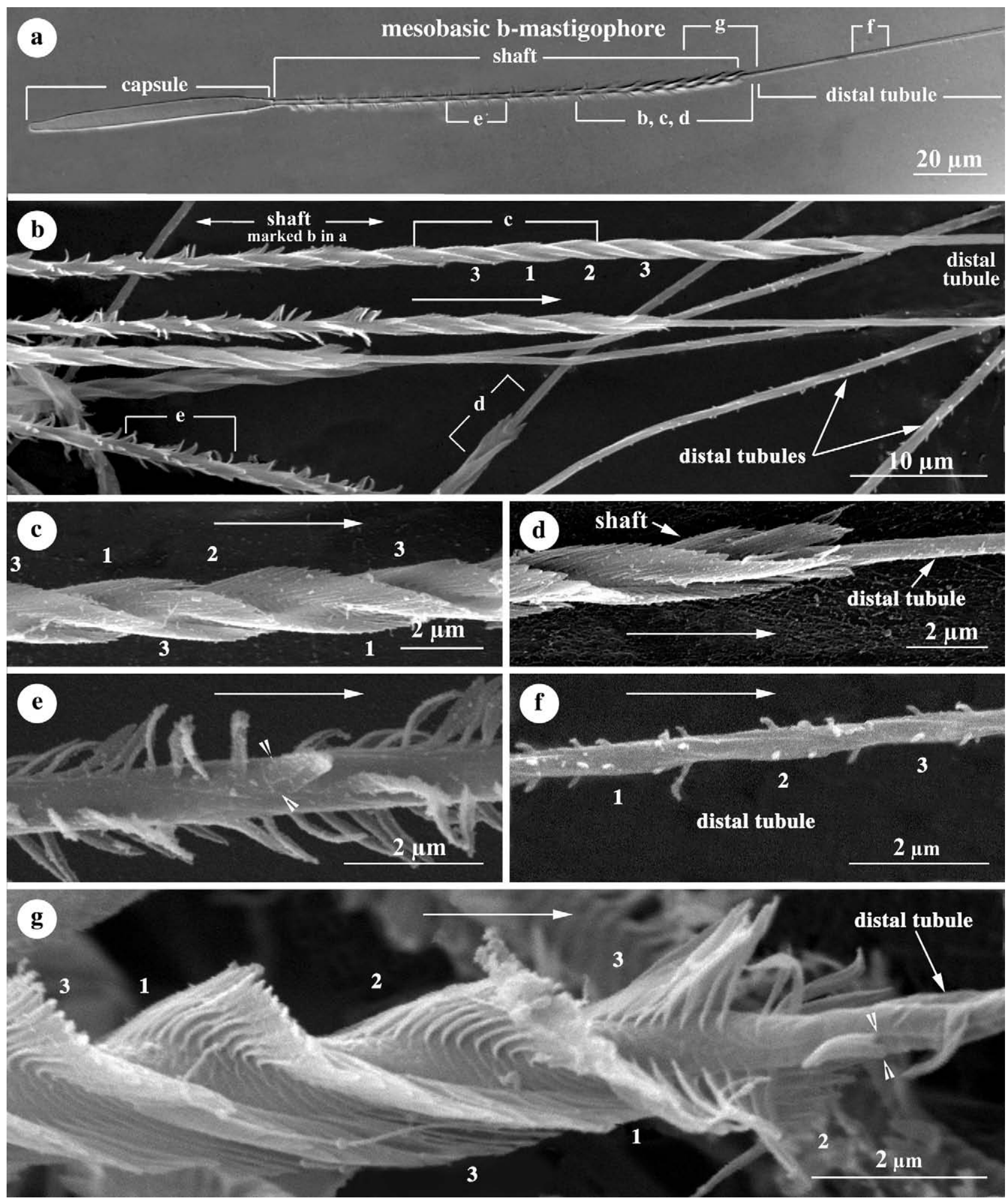

FIG. 3. - Mesobasic b-mastigophores, large, discharged (b-g; SEMs). a,b) Showing location of enlargements of different shaft regions and distal tubules for Figures c-g. b-d) Note right-handed helices of 3 rows of closely-set spines pointing in direction of eversion. d) Shows abrupt transformation of shaft armature into less-spined distal tubule. e) Broad based spines on proximal shaft face outwards and are less dense than spines on main shaft in Figures c,g. f) Part of distal tubule with 3 rows of small, slender, sparse spines. g) Shows right-handed helices of large spines attached to main shaft by their broad bases. Folds on shaft wall correspond to attachment sites of each spine. Note gradual transformation of shaft tubule into distal tubule. Hollow arrow heads point to spine bases; long arrows point in direction of eversion; 1, 2, 3, three spine-rows. 

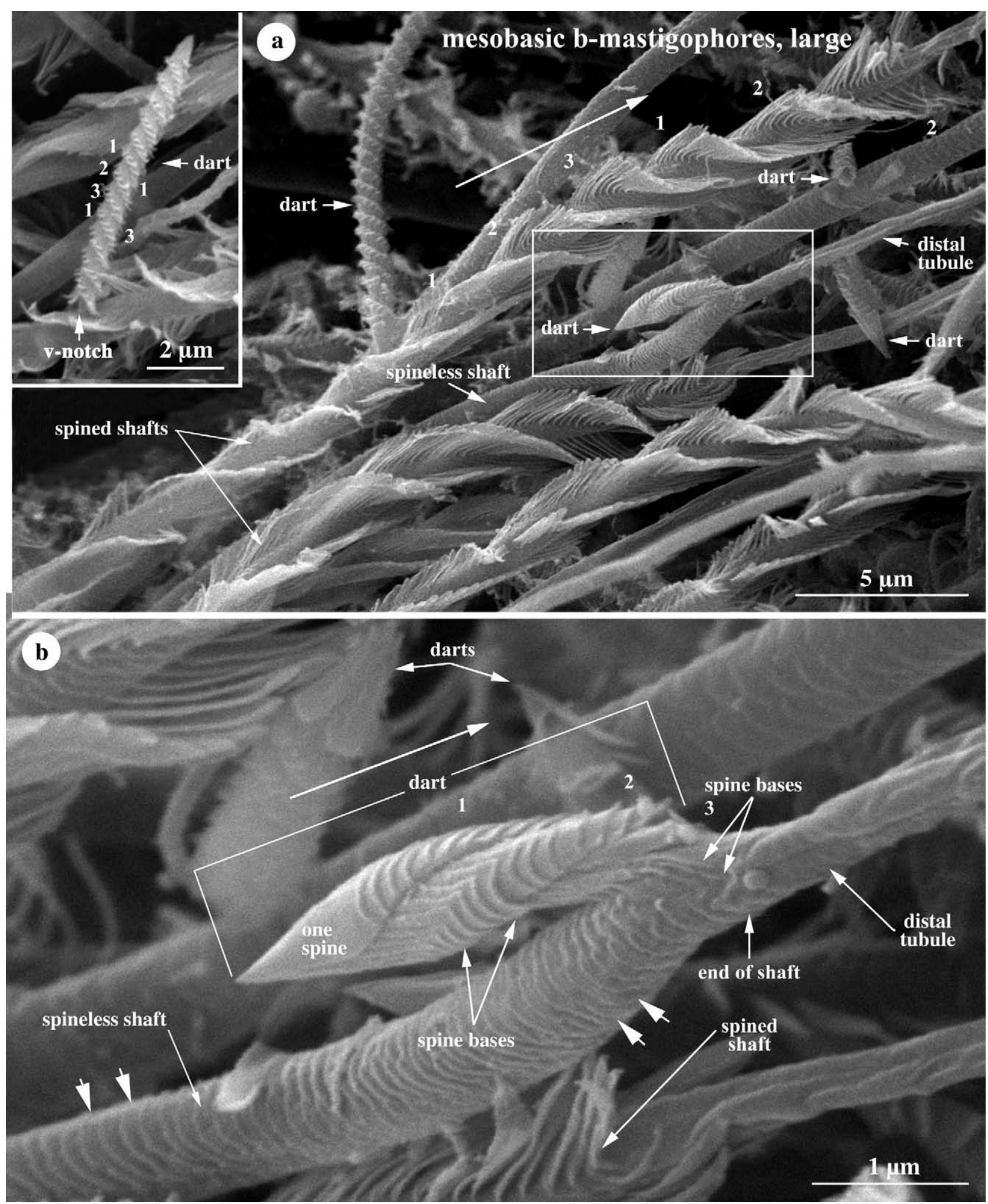

FIG. 4. - Mesobasic b-mastigophores, large, discharged (SEMs), showing shafts, tubules and darts. a,b) Discharged shafts with spines pointing in direction of eversion or else spineless. 3 spine-rows form right-handed helices. Note darts. Inset a: A dart with left-handed helices of spine-rows and V-shaped notch at end. b) Enlargement of square from Figure a shows a short, arrow-tipped dart still attached by its spine bases to end of a spineless, everted shaft. The dart shows 3 left-handed helical spine-rows and a transverse pattern of spine bases. Note folds of the spineless shaft-wall (short arrows). A spine from each of the three spine-rows has earlier been attached on each fold. Long arrows point in direction of eversion; short arrows point to attachment marks of spine bases and folds on shaft wall; v-notch, V-shaped notch; 1, 2, 3, three spine-rows. 

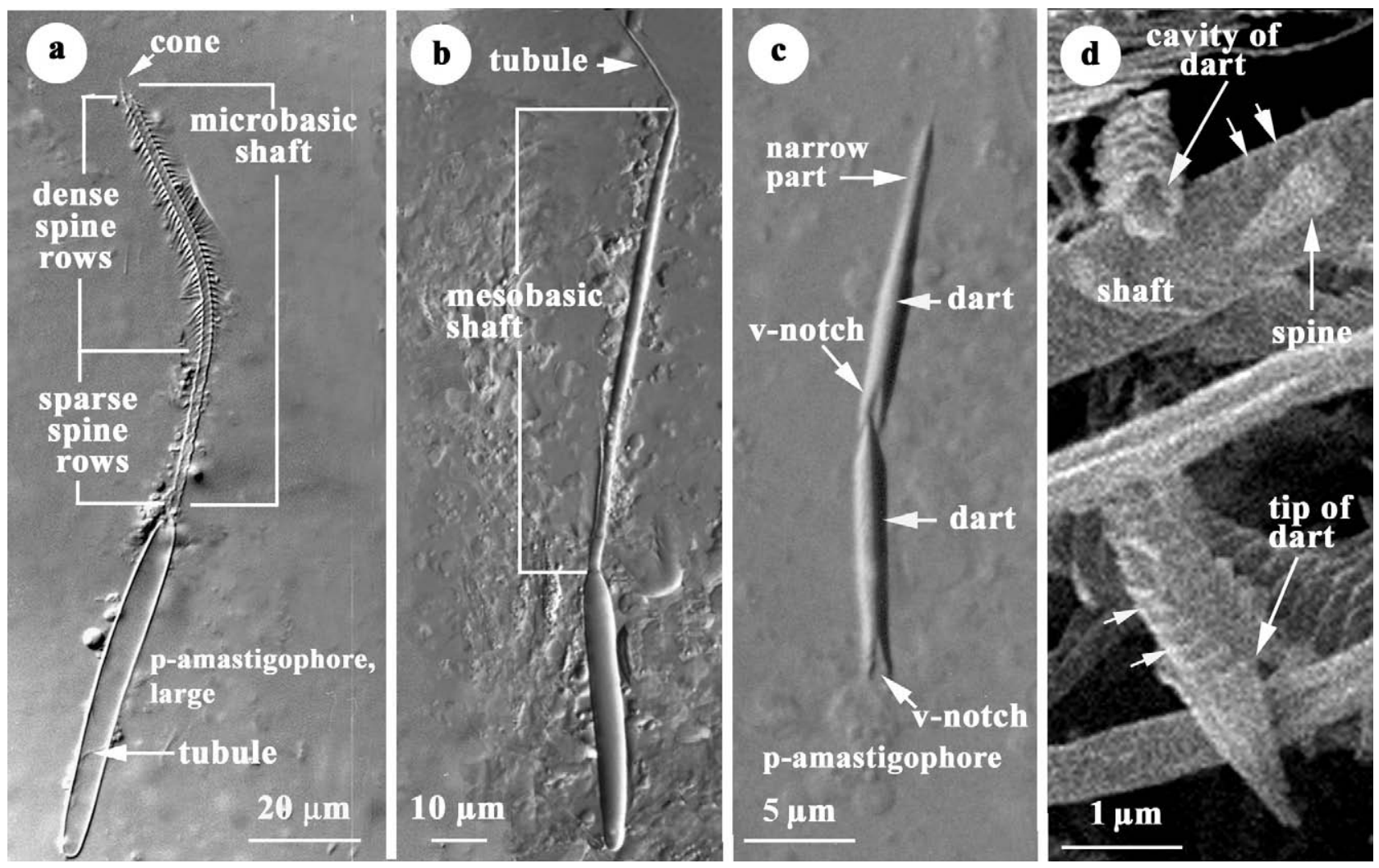

FIG. 5. - p-amastigophores, large, discharged and darts. a) Microbasic shaft with a terminal cone; proximal shaft with sparse spine-rows and slightly folded wall; main shaft with dense spine-rows. b) Mesobasic spineless shaft with tiny tubule distally. c) Broken p-amastigophore dart with V-shaped notches. Note upper narrow part. d) Two broken darts from a b-mastigophore (SEM). Upper dart hollow; lower dart with transverse striations from spine bases. Short arrows point to transverse striations; v-notch, V-shaped notch.

mastigophore darts were present in one squash preparation. The longest $b$-mastigophore darts found were up to $40 \mu \mathrm{m}$ (Figs. 2e,f, 4a); the shortest darts, 1-2 $\mu \mathrm{m}$ long, resembled arrowheads (Fig. 4b). Large meso- and microbasic p-amastigophores (discharged shaft length 48.2-85.0 $\mu \mathrm{m}$ ) also formed darts (up $27 \mu \mathrm{m}$ long) (Figs. $5 \mathrm{c}, 7)$. A few darts, up to $13 \mu \mathrm{m}$ long, were found on medium-tentacle $\mathrm{p}$-amastigophores (discharged shaft length 18.0-30.5 $\mu \mathrm{m}$ ) (Fig. 1c). Small darts occasionally occurred at the end of partly everted or everted shafts of small, drop-shaped mesentery p-mastigophores.

Darts were formed of the three rows of shaft spines, which as in the inverted shaft are set in left-handed regular helices (Figs. 1a, inset, 4a, inset, 7b-d). Darts were typically found near everted shafts which lack spines. Corresponding to the length-range of darts, shafts may lack spines altogether (Figs. 4, 7a), whereas other are spineless in the mid- or basal region, or are armed only in a short distal region (Fig. 2c).

In Figure 4 a small b-mastigophore dart is seen on a spineless mesobasic shaft just before its transition to the distal tubule. This dart consists of three spinerows (Fig. 4b, 1, 2, 3) forming left-handed helices. The spines are neatly laid on top of each other with their tips trapped by spines ahead of them. The dart is attached to one side of the shaft by the spine bases of the last spine-row (Fig. 4b). The fine transverse striations on the dart correspond to spine bases. The striations on the spineless shaft correspond to folds (Fig. 4b, small arrows). Attachment marks from the detached spines are not visible (Fig. 4b). If the spine bases point outwards they do not give the effect of transverse striation (Fig. 1a, inset). The last 2 spines rows of the dart end form the V-shaped notch (Figs. 2e, inset, 4a, inset).

Darts of large and medium p-amastigophores were attached to the end of spineless shafts (Figs. 1c, 7) or to the tiny everted tubule. In newly-made LM preparations, darts of large p-amastigophores were seen attached at end of the tiny tubule as it everted, moving in circles with the advancing tubule. In Figure 7 a long pamastigophore dart is attached to a spineless shaft, but for a few spines at its distal end (Fig. 7d). The dart consists of 3 spine-rows forming left-handed helices, and the spine bases form transverse striations (Fig. 7c,d). The striation is lost (Fig. 7b,c) in the distal and middle dart, where the spine bases point slightly outward. The $\mathrm{V}$-shaped notch was visible at end of the two pieces of the broken p-amastigophore dart (Fig. 5c). With one exception (Fig. 5c) the darts of the p-amastigophores were uniform in width (Figs. 1c, 7).

Darts consisted only of spines interlocked with each other and were easily broken. The long, narrow b- 

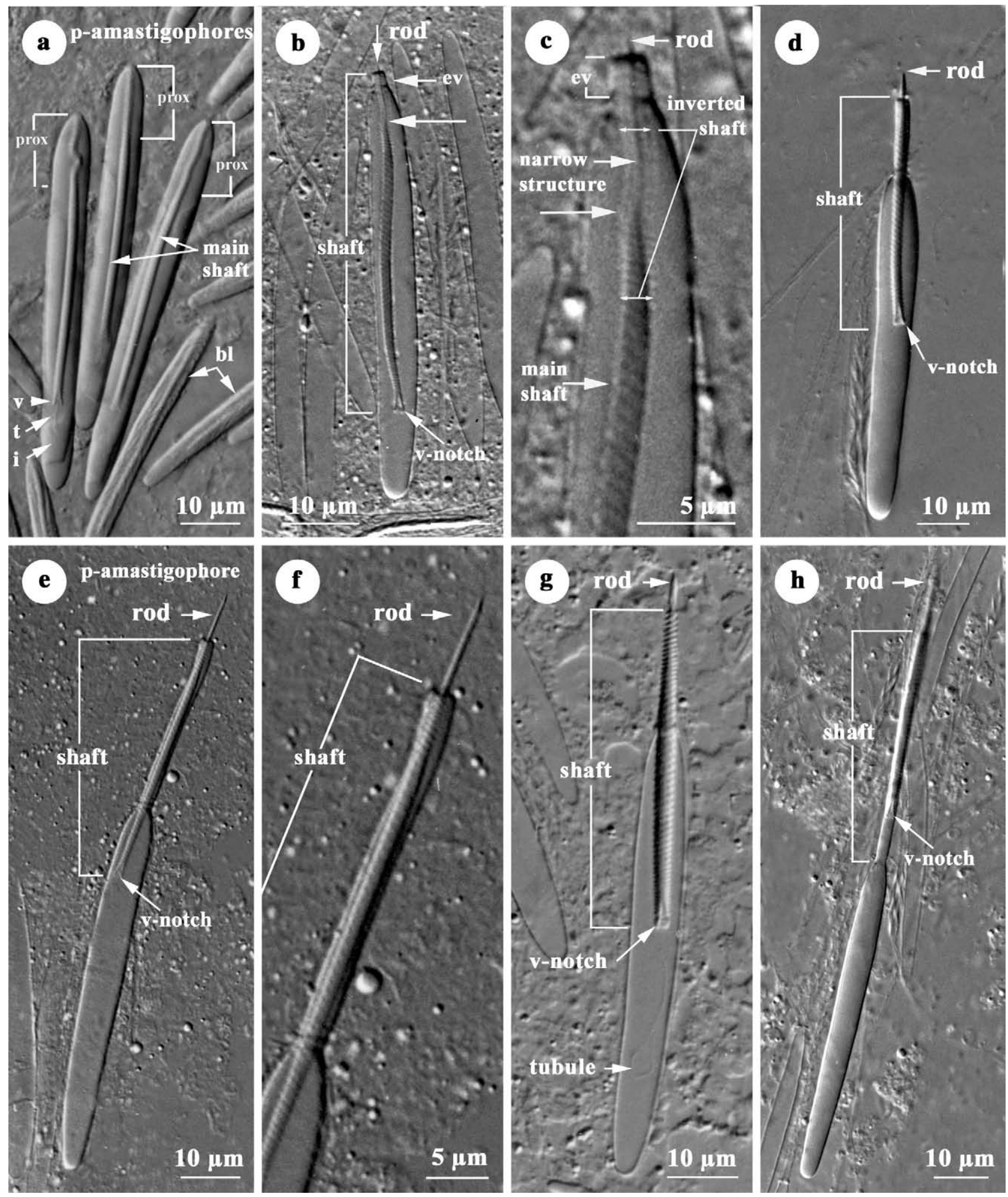

FIG. 6. - Acontia p-amastigophores, large; b-h) partly discharged. a) Note one p-amastigophore with undulating proximal shaft (prox). b-h) Note increased length of pointed rod and position of V-shaped notch as shafts evert. b,c) An immature p-amastigophore. Note tight helices on proximal shaft and wide helices on main shaft. c) Enlargement of Figure b. Note thin rod pointing out of short, everted shaft and inside broad, inverted proximal shaft. d) Note clearly delimited rod at end of partly everted shaft. e,f) Note long, pointed rod and helices on inverted main shaft inside partly everted shaft. f) Enlargement of Figure e. g) Note rod, helices on shaft partly outside capsule and tubule inside flattened capsule. h) V-shaped notch visible in partly everted shaft. $b l$, b-mastigophores, large; ev, everted shaft $i$, internal structure; long arrow points to border between proximal and main shaft; prox, proximal shaft; $t$, tubule; $v$, $v$-notch, $\mathrm{V}$-shaped notch. 

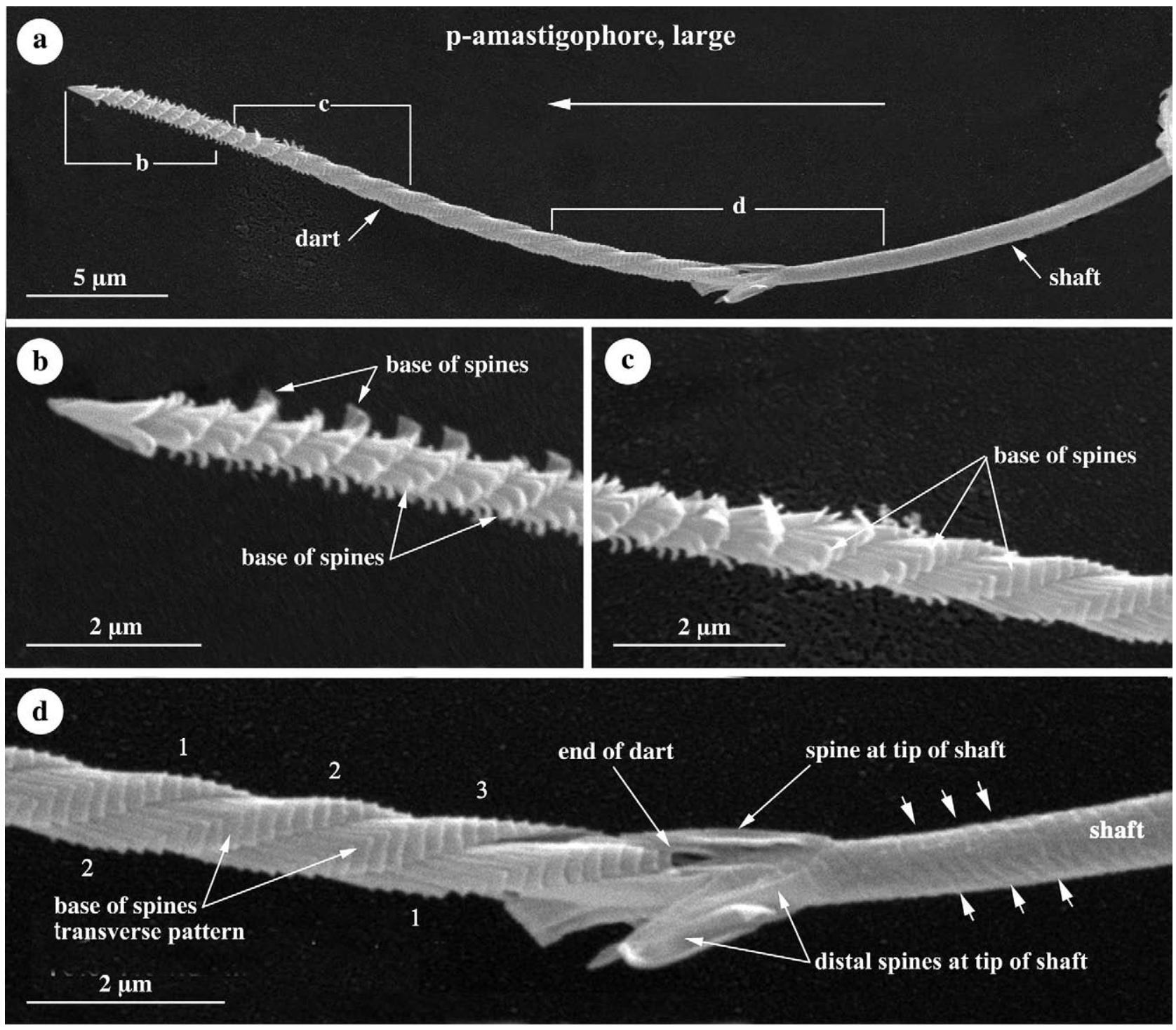

FIG. 7. - A p-amastigophore with a long dart (SEMs) attached to end of everted shaft. Spines of dart point in direction of eversion, their tips hidden below spine bases ahead of them. a) Overview showing locations of enlargements for Figures b-d. b) Distal dart showing left-handed helices of spines, their bases facing outward. c,d) Middle and basal dart showing left-handed helices of spine-rows. When not facing outwards the spine bases show a transverse striation. d) Note right-handed helically striations on everted spineless shaft. A few distal spines still attached

to tip of main shaft. Long arrow points in direction of eversion; short arrows point at transverse striations; 1, 2, 3, three spines-rows.

mastigophore darts were often broken into two or more smaller darts (Figs. 2f, 4a). Figure 5d shows the empty cavity of a broken b-mastigophore dart. The slightly broader darts of p-amastigophores (Figs. 5c, 7) are built by longer spines than those of b-mastigophores, and do not seem to break similarly into small pieces.

\section{Eversion and unexplained structure}

During the late development of immature p-amastigophores a narrow rod-shaped structure was clearly seen inside the inverted proximal shaft with tight helices (Fig. 6b,c, see Östman et al., 2010). This structure was indistinct in mature p-amastigophores (Fig. 1b). Figure $6 b, c$ shows the immature p-amastigophore at an early stage of discharge. The proximal shaft starts the eversion and the narrow rod starts to point out from the short everted shaft. The rod is clearly delimited from the broader shaft and continues inside along the proximal inverted shaft. It broadens basally, and at the border between proximal and main shaft it has the width of the inverted shaft.

As the eversion proceeded the everted shaft and the rod progressively grew longer and the $\mathrm{V}$-shaped notch at shaft end came closer toward the proximal capsule (Fig. 6b-h). The V-notch is inside the partly everted shaft in Figure 6h. The rod in Figure 6e,f is long and the helices of the non-everted portions of the shaft is visible inside the partly everted shaft. In Figure $6 \mathrm{~g}$ the inverted shaft is partly outside the capsule and has a dis- 
tinct rod at its end. The focus is on the back of the shaft explaining the apparent right-handed helices. From the $\mathrm{V}$-shaped notch at the base of the undischarged shaft, the inverted tiny distal tubule can be seen making some loops. Partly discharged p-amastigophore shafts, with an attached rod, were spineless (Fig. 6d-f,h).

\section{DISCUSSION}

\section{Dart formation}

The present investigation on Metridium senile nematocysts confirms that darts are formed by spines detached from the shaft. They are built by closelypacked spines forming left-handed helices similar to that of the inverted shaft (Figs. 1a, 1a, inset, 4, 7) but, unlike the right-handed triple helices of spine-rows, shown on everted shafts of the large b-mastigophores (Fig. 3b-d,g). The strict formation of the dart is contrary to the opinion of Cutress (1955), who could not see how sloughed-off shaft armature could on every occasion form a precise and similar structure. The fine, transverse striations on darts, from the uncovered broad bases of detached spines (Figs. 4b, 7b-d), were observed by Cutress (1955) and tentatively proposed to be formed by spines.

It is not known how the spines adhere together when darts are formed, or what causes spines to detach from the shaft. Weill (1934, p. 145) commented that spines did not seem to be very firmly attached, especially in "rhabdoides", and illustrated (p. 144, Fig. $121)$ a microbasic amastigophore (= p-amastigophore) of $M$. senile (as $A$. dianthus) with a spineless shaft and detached spines scattered nearby. Further, Weill (1934) commented that in certain other "rhabdoides" the shaft spines were just as liable to detach but they did not disperse and remained firmly stuck to each other, so he found a kind of sharp-tipped barbed harpoon next to or in contact with the spineless, everted shaft, often at its tip (p. 144, Fig. 122). Weill often found that the dart represented only a part of the spine-armature, and that especially the b-mastigophore darts were easily broken. Weill's illustrations (p. 144, Figs. 123-125,) showed acontia b-mastigophores of $M$. senile (as $A$. dianthus).

The b-mastigophore darts seemed more slender than those of the p-amastigophores and were more varied in length. As hollow cylinders (Fig. 5d) formed by detached helical rows of spines adhering to each other, the darts seemed to fragment easily. Schmidt (1969) noted that the coarser p-amastigophore darts did not break into smaller pieces so easily as the slender b-mastigophore darts. Further, Schmidt remarked that darts built by the more spaced spine-rows from the bmastigophore shafts were looser structures than darts built by the dense spine-rows of the p-amastigophores. In addition, we think that the larger spines of the pamastigophore extended deeper in under the spines ahead of them, thus giving the dart a better stability than the shorter b-mastigophore spines. The pointed tip and indented $\mathrm{V}$-notch of all darts are explained by the arrangement of spines.

England (1982) thought that darts might be formed when spines were agglutinated to each other at their tips and were thus forced to detach from the shaft as it everted. He noticed that in some darts the spines bases were pointing outward. The spine bases may have been torn outward during the eversion before they were detached from the shaft (see our Figs. 1a, inset, 7b,c). The attachment sites of the spines correspond to folds on the shaft (Figs. 3g, 4b). On each fold one spine from each of the three spine-rows has earlier been attached (see Fig. 3g).

There is little evidence of the force needed to remove the spines from the shaft. Spines are formed at early stages of shaft differentiation (see Östman et al., 2010). Schmidt (1969) suggested that if normal discharge were hindered, changes in intracapsular pressure combined with the elastic properties of the shaft could cause local detachment of spines, if the shaft wall was compressed. A densely helically folded proximal shaft region ("faltstuck") is crucial for producing a dart (Schmidt, 1969). In our study darts were, however, more frequently produced by the large b-mastigophores with their less conspicuous proximal shaft than by the large p-amastigophores with their densely folded proximal shaft wall. Further, Schmidt implied that the pressure on the shaft during discharge decreased distally, sometimes leaving distal spines still attached, and (as mentioned also by England [1982]) these distal spines can normally be folded outwards as eversion continues. The decreasing pressure in the distal inverted shaft may explain the following three events. 1) The presence of everted distal spines on the otherwise spineless mesobasic shafts of our b-mastigophore (Fig. 2c). 2) The attachment of our small b-mastigophore dart by some of its distal spine to the shaft end (Fig. 4b). 3) The few distal spines not included in the dart at end of the otherwise spineless shaft of our p-amastigophore (Fig. 7d).

The observation made by Cutress (1955) of a dart within the lumen of an undischarged shaft, neatly fitting over the shaft end, can perhaps be explained by the theory of Schmidt (1969) that due to increased pressure inside the still inverted shaft, spines can detach and form a dart inside the shaft before eversion.

England (1982) considered that dart formation adds a higher resistance to the discharging shaft, which is supported by our LM observation. We noted that pamastigophores producing darts everted more slowly than those without darts. Long, narrow shafts armed with a large number of dense spines may need a greater force to evert than shorter and broader shafts armed with less dense spines. This may explain why darts were more commonly formed by the long, narrow shaft of the mesobasic b-mastigophores than by the shorter, broader shafts of the p-amastigophores. In agreement with Conklin et al. (1977), we found that most darts 
were formed by large acontia nematocysts and not by medium tentacle nematocysts. The shorter shafts of the tentacle nematocysts compared with the acontia nematocysts might be an explanation. Conklin et al. (1977) remarked that darts formed by partly discharged shafts may have been halted part-way through discharge; the dart may act as a plug or somehow interfere with eversion.

Darts originating from b-mastigophores were homogenous (Figs. 2e,f, 4a, inset), but so were most darts formed by heterotrichous p-amastigophores. The long homogenous dart attached to the everted shaft of a pamastigophore seemed to be formed by broad spines equal in size (Fig. 7) originating from the denselyspined main shaft. The upper piece of the broken $\mathrm{p}$ amastigophore dart in Figure 5c is, however, distally more narrow than its basal part. Perhaps the narrow part was formed by the slender, sparse spines from the proximal shaft (see Östman et al., 2010).

In the cubozoan Carybdea alata Yanagihara et al. (2002) described a structure referred to as a lancet detached from euryteles. In their SEM pictures and illustrations (Figs. 1D, 2B, 3A), the lancet seemed to be built of spines from the shaft in a manner similar to dart formation in Metridium. The spines were neatly placed upon each other, leaving the spine bases uncovered forming the transverse pattern on the lancet. The shaft was spineless with transverse striations marking the attachment sites of detached spines. The lancet might thus be identical with darts described in Anthozoa.

Whether darts have a function is unclear (Hand, 1961; England, 1982). They may be artifacts, since they appear only irregularly in the preparations. Their presence may depend on the way the squashes are made. However, Conklin et al. (1977) discussed the possibility that darts might have some selective advantage to benthic sea anemones in defence against nudibranchs. Detachable arrows would be advantageous in deterring a potential predator, compared with nematocysts, which anchor the prey to the anemone.

We confirm the conclusion of Schmidt (1969), Conklin et al. (1977) and Daphne Fautin (personal communication) that the category microbasic q-mastigophore, established by Cutress (1955) for nematocysts with a detachable dart at end of the inverted shaft, is unjustified, because a dart can be formed by many various nematocyst types.

\section{Unexplained structures}

The internal thin, rod-shaped structure visible inside the proximal shaft of immature p-amastigophores (Fig. 6b,c) and faintly observable in mature capsules (Fig. 1b) may be formed by capsular matrix. This narrow structure was illustrated in undischarged amastigophores (= p-amastigophores) of $M$. senile and $M$. farcimen (Kramer and Francis, 2004, Fig. 4A,C,G). As the proximal shaft matures and becomes more tightly folded and shorter, the thin rod-shaped structure may condense and shorten to match the shorter length of the inverted proximal shaft. When eversion starts, the narrow rod, clearly delimited from the everting shaft, is pushed ahead of the everting shaft (Fig. 6c-h) and becomes ever longer as the shaft everts. Perhaps the rod gets its pointed shape when pressing through the capsule aperture as the three capsular flaps are turned aside to open the capsule (Westfall and Hand, 1962). The pointed rod may have a penetrating function.

Perhaps Cutress (1955) interpreted the rod ahead of the everting shaft as the tip of a dart. If so, he was right in claiming that the shaft was not spineless after ejecting a dart. A long, narrow rod has been noted at the tip of a dart still attached to the end of a mesobasic spineless shaft of a large p-amastigophore of the sea anemone Sagartiogeton viduatus (Östman et al., in preparation).

\section{ACKNOWLEDGEMENTS}

(See Östman et al., 2010). We especially thank Dr. Elaine Robson and Dr. Paul Cornelius for their most helpful work on the manuscript and Dr. Daphne Fautin, as a referee, for her invaluable assistance with the improvement of our manuscript.

\section{REFERENCES}

Conklin, E.J., C.H. Bigger and R.N. Mariscal. - 1977. The formation and taxonomic status of the microbasic q-mastigophore nematocyst of sea anemones. Biol. Bull., 152: 159-168.

Cutress, C.E. - 1955. An interpretation of the structure and distribution of cnidae in Anthozoa. Syst. Zool., 4: 120-137.

England, K.W. - 1982. On certain Actiniaria of the Indian and Pacific Oceans. M. Ph. D. University of Reading, UK

Hand, C. - 1961. Present state of nematocyst research: Types, structure and function. In: H.M. Lenhoff and W.F. Loomis (eds.), The Biology of Hydra, pp. 187-202. Univ. Miami Press, Coral Gables, Florida.

Iwanzoff, M. - 1896. Uber den Bau, die Wirkungsweise und die Entwicklung der Nesselkapseln der Coelenteraten. Bull. Soc. Nat. Moscow, N. S., 10: 95-161 and 323-354.

Kramer, A and L. Francis - 2004. Predation resistance and nematocyst scaling for Metridium senile and M. farcimen. Biol. Bull., 207: $130-140$

Östman, C. - 1987. New techniques and old problems in hydrozoans systematic. In: J. Bouillon, F. Boero, F. Cigogna and P.F.S Cornelius (eds.), Modern trends in the Systematics, Ecology and Evolution of Hydroids and Hydromedusae, pp. 67-82. Clarendon Press, Oxford.

Östman, C. - 2000. A guideline to nematocyst nomenclature and classification, and some notes on the systematic value of nematocysts. Sci. Mar., 64(Sup. 1): 31-46.

Östman, C., W.R. Kem and S. Pirano. - 1991. Nematocysts of the Mediterranean hydroid Halocordyle disticha. Hydrobiologia, 216/217: 607-613.

Östman, C., J. Roat Kultima, C. Roat and K. Rundblom. - 2010. Acontia and mesentery nematocysts of the sea anemone Metridium senile (Linnaeus, 1761) (Cnidaria: Anthozoa). Sci. Mar., 74(3): 483-497.

Schmidt, H. - 1969. Die Nesselkapseln die Aktinien und ihre differentialdiagnostische Bedeutung. Helogol. Wiss. Meeresunters., 19: $284-317$.

Weill, R. - 1934. Contribution à l' étude des cnidaires et de leurs nématocystes. I, II. Trav. Stn. zool. Wimereux, 10-11: 1-701.

Westfall, J.A. and C. Hand. - 1962. Fine structure of nematocysts in a sea anemone. In: S.S. Breese, Jr. (ed.), Conf. Electron. Microsc. 5 (Philadelphia), M-13. Academic Press. 
$\mathbf{5 1 0} \bullet$ C. ÖSTMAN et al.

Yanagihara, A.A., J.M.Y. Kuroiwa, L.M. Oliver, J.J. Chung and D.D. Kunkel. - 2002. Ultrastructure of a novel eurytele nematocyst of Carybdea alata Reynaud (Cubozoa, Cnidaria). Cell Tissue Res., 308: 307-318.
Scient. ed.: P.J. López-González.

Received January 13, 2009. Accepted November 11, 2009.

Published onlline May 14, 2010. 